\title{
La locución deportiva en Tenerife: Evolución y características. Tres generaciones del periodismo radiofónico deportivo.
}

\author{
Radio announcement in Tenerife: evolution and features. Three generation \\ of radio sport journalism
}

\author{
Escarlata Dios García \\ Universidad de La Laguna (España) \\ sdiosg@hotmail.com
}

Recibido: 20 de noviembre de 2012

Aceptado: 15 de diciembre de 2012

\begin{abstract}
Resumen
La voz es la herramienta principal e imprescindible para transmitir información a través de la radio. Por esto, los profesionales de este medio de comunicación deben prestar especial interés en su cuidado y formación.

Comunicadores y periodistas de la radio deportiva en Tenerife nos han dado su opinión y han compartido su experiencia, para obtener una clara definición de lo que serían las recomendaciones y pasos a seguir para la mejora de la locución radiofónica deportiva.

Asimismo, se ha pretendido realizar una aproximación al recorrido de la radio deportiva en la isla de Tenerife, con el fin de ver y explicar de modo breve, cómo se ha desarrollado esta área de la profesión periodística, cuáles han sido los cambios más relevantes en su desarrollo y observar las diferencias entre el modo de hacer radio deportiva en los comienzos de esta disciplina en Tenerife y la actualidad.

Con todo ello se ha querido establecer las pautas generales de lo que sería una buena locución deportiva, cuáles serían sus características, lo que reclama la audiencia específica de este tipo de radio y el modo de formación de la voz de los locutores y periodistas deportivos en Tenerife.
\end{abstract}

\section{Abstract}

The voice is the main and essential tool for transmitting information over the radio. For this reason, this means of communication professionals should pay special interest in your care and training. 
Communicators and journalists from the sports radio in Tenerife have given us their opinion and have shared your experience, for a clear definition of what would be the recommendations and steps to follow for the improvement of sports radio announcer. Also has tried make an approximation to the path of the sports radio on the island of Tenerife, in order to see and explain in brief mode, has developed this area of the journalistic profession, what have been the most significant changes in its development and observe the differences between the way of doing sports radio at the beginning of this discipline in Tenerife and

today.

With all this they wanted to establish the guidelines General of what would be a good sporting phrase, what would be its features, which claims the specific of this type of radio audience and training mode of the voice of sports in Tenerife the announcers and journalists.

Palabras Clave: Radio, deporte, Tenerife, locución, cuidado de la voz.

Key Words: Radio, sport, Tenerife, announcement, voice care.

\section{Introducción}

Esta investigación se ha concebido con el fin de realizar un primer acercamiento a la locución radiofónica deportiva en Tenerife. El interés por ella, nace de la mano de la motivación de la propia autora por conocer los entresijos de esta parte de la profesión periodística. Asimismo, se pretende indagar sobre la necesidad de una formación vocal adecuada y sobre los aspectos teóricos y prácticos relacionados con la narración deportiva, una labor que cada fin de semana llevan a cabo numerosos profesionales de la radio en Tenerife y que para nada se muestra fácil de llevar a cabo. Se trata también de mostrar la gran necesidad del cuidado de la voz para ejercer un buen trabajo comunicativo.

En este estudio pretendemos no solo realizar un exhativo análisis de cómo se encuentra la situación en el medio radiofónico en Tenerife, sino ver cómo han evolucionado las técnicas narrativas, así como comprobar si lo han hecho de forma positiva o negativa.

Se intenta conseguir, además ver cuales son las voces que más agradan a la audiencia, con el objeto de poder calibrar si se capta de forma satisfactoria a los tinerfeños que escuchan radio deportiva, observar de qué forma podría imprimirse esta necesidad en aquellos que no son habituales oyentes de esta radio especializada. 


\section{Metodología}

\subsection{Marco teórico: La Locución deportiva}

Cuando un locutor expone su discurso durante cualquier retransmisión, sea deportiva o no, está dirigiéndose a un público. A los oyentes les tiene que llegar la información de forma eficaz, para la que comprendan. Una mala vocalización y manejo de la voz puede ocasionar una importante pérdida de calidad de del mensaje, que puede derivar en un descenso de la audiencia del medio en cuestión. González Ávila, Carlos, nos habla de ello en su tesis doctoral:

"Hay que tener en cuenta que el oyente es lo primero y le debemos fidelidad y procurarle un tratamiento digno en todo momento, porque en estos tiempos de proliferación de medios informativos y de encarnizadas competencias hay que cuidar a la audiencia" 1

Puede darse el caso de que un mensaje esté perfectamente redactado, pero mal leído. El periodista debe formase en redacción, pero también en locución. De nada sirve un perfecto contenido sin una forma exquisita, aunque tampoco al revés. Contenido y estética de los mensajes deben ir de la mano, ya que esa será la única manera que conseguir que el oyente tenga una información de completa calidad.

En los tiempos que corren es necesaria una buena calidad en los mensajes, ya que esto tendrá una repercusión económica en términos de publicidad para las empresas de comunicación.

De igual forma que cuando un invitado viene a nuestra casa, sacamos la mejor vajilla que tenemos, el oyente merece una distinguida atención. La persona que se encuentra en su casa, coche, trabajo, etc., y enciende el aparato de radio con el fin de informarse, entretenerse y también formase, espera comprender lo que le transmite el locutor, ya que de lo contrario, cambiará de dial hasta encontrar otra emisora capaz de suplir sus necesidades.

Los oyente merecen todo el respeto por parte de los periodistas y locutores o comunicadores. Una primera forma de mantener la educación hacia ellos es no gritarle al micrófono. El contenido hay que darlo atendiendo a unas formas, unas reglas básicas, que luego cada uno adapte a su estilo, pero siempre de forma que se transmita el mensaje de manera efectiva y comprensible.

1 González Ávila, Carlos. 2010. "Estética de los mensajes audiovisuales: el cine como soporte didáctico", Universidad de La Laguna.

Facultad de Ciencias de la Información - Universidad de La Laguna

Avenida César Manrique, s/n; Campus de Guajara

38071 La Laguna, Tenerife (Islas Canarias - España) 
En la locución deportiva en Tenerife grandes narradores han captado a miles de personas a través de las ondas a lo largo del tiempo. César Fernández Trujillo de Armas, Mayte Castro, Juan Carlos Castañeda, Domingo Álvarez, son solo algunos ejemplos de horas y horas de dedicación y trabajo.

"Radio Juventud de Canarias" o la "SER" impartían cursos de técnica vocal y enseñaban a sus locutores, que a pesar de no tener el título de periodista, eran excelentes comunicadores, a transmitir a los oyentes el mensaje. ¿Cuántas emisoras hacen eso en la actualidad? Es más, hoy, que la Universidad de La Laguna ya tiene el Grado en Periodismo, ¿cuántos locutores y comunicadores están formados?, ¿cuántos forman y cuidan su voz? ¿Cuidaban su voz los locutores de generaciones pasadas?, ¿y los de ahora? No se trata de criticar a nadie, sino de dar una visión completa de cómo se encuentra la locución deportiva, de captar la opinión de los propios profesionales de los medios y de demostrar que la voz es, no solo una herramienta esencial a la hora de llegar al oyente, sino quizá la principal en la radio y por ello, y en propio beneficio ya no solo de los receptores, sino también de los emisores, hay que cuidarla.

Cierto es que "cada maestrillo tiene su librillo", pero unas pautas generales nunca viene mal.

\subsubsection{Recomendaciones básicas para cuidar la voz}

¿Por qué es importante la formación vocal? Tres de las cuestiones básicas que un locutor o narrador debe seguir a la hora de ponerse ante el micrófono son: la predisposición, la actitud positiva y la vocación. Vamos a decir que hay dos tipos de locutores: los que nacen y los que se forman. Pero estos que nacen, también necesitan una formación. De nada sirve la genética si no se cuida. Podemos nacer con un cuerpo perfecto y una inteligencia suprema, que si no se cultivan se vuelven inservibles.

Quien no tiene una voz privilegiada por el factor genético también puede llegar a desarrollarla. Las profesoras Blanch, Margarita y Lázaro, Patricia, nos explican en su obra "Aula de locución"2 que Demóstenes ${ }^{3}$ era tartamudo y siguiendo un "estricto programa de reeducación oral" ${ }^{4}$ consiguió trabajar su voz y superar su problema. Pero, no tenemos que irnos hasta la Grecia clásica para demostrar este hecho. Más adelante, describiremos la experiencia de "Aula de locución". Más adelante, describiremos la experiencia de

\footnotetext{
${ }^{2}$ BLANCH, Margarita; Lázaro, Patricia. (2010) Cátedra, Madrid.

${ }^{3}$ Demóstenes era uno de los oradores más relevantes de la historia Griega. Además, también era un destacado político ateniense.

${ }^{4}$ BLANCH, Margarita; Lázaro, Patricia. (2010) “Aula de locución”. Cátedra, Madrid
} 
profesionales como Mayte Castro que, gracias a una logopeda, dejó atrás las disfonías ${ }^{5}$ que se le presentaban tras cada narración. Lo primero y más importante para locutar bien es saber respirar. Todos respiramos, de lo contrario moriríamos, pero no todos sabemos respirar para hablar o realizar una locución. De aquí parten la mayoría de las patologías que afectan a nuestra voz.

La respiración es "el motor de nuestra voz y el aire su combustible. Para dominar la voz, antes que nada, debemos conocer, practicar y dominar el mecanismo de respiración"6.

Por ello, lo primero a lo que debe enfrentarse un locutor y, cuanto más un narrador, ya que expone su voz a una serie de factores nocivos, es a afrontar una correcta técnica de respiración.

Con una buena respiración conseguiremos mejorar la proyección de la voz. Al aplicar una buena técnica respiratoria, "(...) que nos dé la cantidad de aire y control suficiente del soplo para hablar con comodidad, sin sensación de ahogo, y a la intensidad más adecuada al contexto comunicativo concreto"7 conseguimos una proyección adecuada que capte la atención del oyente, y no molestarle produciendo gritos.

Para respirar bien debemos controlar nuestra capacidad diafragmática, tomar una postura adecuada frente al micrófono, realizar diariamente los ejercicios de técnica vocal recomendados por los expertos, así como los de relajación, etc.

Otro de los puntos claves a la hora de cuidar nuestra voz y mejorar nuestra capacidad, para conseguir una locución excelente, se encuentra en la higiene que debemos llevar diariamente. No fumar, no exponer nuestra voz a cambios de aire fuertes, no tomar cosas ni muy frías, ni muy calientes, etc., son recomendaciones básicas.

Es importante también asistir a revisiones, pero no solo en caso de ver afectada nuestra voz. Si somos profesionales, debemos serlo al cien por cien, y ello requiere un adecuado tratamiento de nuestra herramienta de trabajo. Si a un narrador cuando llega al estadio, no tiene línea donde engancharse, no podrá retransmitir el partido. Antes de ir al lugar de trabajo, deberá asegurarse que dispone de todas sus herramientas en perfecto estado, para realizar su trabajo. La voz es una de ellas. Un periodista no debería ir a una rueda de prensa sin su material correspondiente para grabarla. Pues lo mismo ocurre con la voz, que deberá

${ }^{5}$ Disfonía: Trastorno de la fonación que afecta a los órganos de producción de la voz. (RODERO ANTÓN, EMMA) (2003):407.

${ }^{6}$ BLANCH, Margarita; Lázaro, Patricia. “Aula de locución”. Cátedra. Madrid, 2010

${ }^{7}$ BLANCH, Margarita; Lázaro, Patricia. "Aula de locución”. Cátedra. Madrid, 2010 
ser revisada, con el fin de que se encuentre en perfecto estado para dirigir al oyente el mensaje con claridad y calidad.

A todas estas recomendaciones hay que añadirle la tecnología. En la actualidad, es vital tener en cuenta el contexto sonoro donde se vaya a realizar la locución o narración. Tal y como afirman las profesoras, Blanch y Lázaro: “al prepara y trabajar nuestra voz deberemos prestar mucha atención al contexto sonoro en el que nos encontraremos, es decir, a las características acústicas del lugar desde donde se habla"8.

No es lo mismo estar en el estudio llevando la continuidad, que en el estadio donde le haya tocado retransmitir al narrador. La voz deberá ir adaptada al contexto espacial y las cualidades de la voz también. La intensidad, el tono y el ritmo deberán ir ajustados a lo que ocurre y al lugar donde se encuentre el locutor. Además, es importante cuidar la distancia que debe tomar el locutor del micrófono. Si el locutor se encuentra muy próximo al aparato, puede provocar un sonido distorsionado. Lo mismo ocurre si se aleja demasiado.

También debemos tener en cuenta la pronunciación. "Lo primero que ha de tener presente el locutor radiofónico es que debe realizar el suficiente esfuerzo articulatorio para lograr una pronunciación correcta"9.

Es importante tener una buena dicción, ya que ello condicionará el entendimiento por parte del oyente del mensaje. La velocidad en el discurso también deberá ser clara. Asimismo, es también importante adoptar un léxico adecuado a la narración o exposición oral de los hechos acontecidos.

Estas son algunas recomendaciones a nivel general. Vamos ahora a centrarnos específicamente en la locución deportiva.

\subsubsection{Reglas básicas para una buena locución deportiva.}

"La narración deportiva ganará en expresividad y belleza si se emplea con efectividad y corrección las variaciones tonales durante la misma. (...) La entonación a lo largo de la retransmisión radiofónica debe ser lo más natural y variada posible con tendencia a reproducir en la medida de lo posible el habla natural del pública para el que se retransmite sin resultar grosero, ni manifestar desinterés por lo que ocurre". (Josep María Blanco, Doctor en Ciencias de la Información por la Universidad Autónoma de Barcelona).

\footnotetext{
${ }^{8}$ BLANCH, Margarita; Lázaro, Patricia. "Aula de locución". Cátedra. Madrid, 2010

${ }^{9}$ RODERO ANTON, Emma. "Locución radiofónica". 2003, Servicio de Publicaciones de la Universidad Pontificia de Salamanca. Madrid, 2003.
} 
Para llegar a los oyentes el narrador debe conocer las características de su voz, ya que así será como único podrá sacarle el máximo partido. El narrador deberá siempre cuidar su principal herramienta de trabajo, así como prepararla antes de cada narración. Blanco, J.M. nos explica que: "resulta vital conocer las característica de su propia voz para optimizar su rendimiento comunicativo en el momento de llevar a cabo parte o toda la narración de un acontecimiento deportivo" ${ }^{\prime 10}$.

En lo que se refiere al tono y a la intensidad, Blanco, J.M., nos recomienda encontrar el tono y la intensidad media, adecuada a cada momento del encuentro que pretendamos retransmitir. Muchos narradores comienzan con una intensidad muy alta desde el principio de la retransmisión, lo que conlleva que, cuando llegue un momento de tensión sobre el terreno de juego su voz no pueda hacer frente a la elevación que debiera. Este hecho puede provocar disfonías.

Blanch, Margarita y Lázaro, Patricia, explican que muchas veces "los receptores acabamos asistiendo a partidos de fútbol o carreras automovilísticas, por ejemplo, en las que la locución pretende sostener una cadencia acelerada y un énfasis continuo que no se corresponde con los cambios de ritmo del propio acontecimiento que puede incluir momentos en los que, incluso, no pasa nada". ${ }^{11}$

Si un narrador aumenta su intensidad puede significar que pretenda llamar la atención para alertar al oyente que algo está a punto de suceder.

Cuando el narrador se dispone a subir la intensidad, muchas veces termina por gritar. Según Blanco, J.M., "A los narradores de retransmisiones de pruebas deportivas por radio se les imagina generalmente como personas que "gritan" continuamente mientras hablan". ${ }^{2}$

Este efecto de "gritar" en lugar de captar la atención del oyente puede producir lo contrario, ya que el receptor de la información al sentirse intimidado, suele recurrir a cambiar de dial o apagar directamente el aparato de radio. Además, existe otro problema derivado del aumento de la intensidad, y es que si el narrador sostiene la intensidad alta durante mucho tiempo seguido puede afectarle de forma negativa a sus cuerdas vocales y provocar disfonía, o alguna enfermedad peor a largo plazo. Blanco, J.M. advierte: "Vaya con cuidado con abusar durante un tiempo prolongado de una intensidad alta, puesto que somete

${ }^{10}$ BLANCO, J.M. (2002) Las retransmisiones deportivas: técnicas de narración radiofónica. Comunicación Global, Barcelona. Pág. 59

${ }^{11}$ BLANCH, Margarita; Lázaro, Patricia. "Aula de locución". Cátedra. Madrid, 2010. Pág. 154

12 BLANCO, J.M. (2002) Las retransmisiones deportivas: técnicas de narración radiofónica. Comunicación Global, Barcelona. pág. 86

Facultad de Ciencias de la Información - Universidad de La Laguna

Avenida César Manrique, s/n; Campus de Guajara

38071 La Laguna, Tenerife (Islas Canarias - España) 
constantemente a un castigo a los pliegues vocales y esto puede traducirse en una afonía" ${ }^{13}$. Además, Lázaro, Patricia y Blanch, Margarita dicen:

"La rotura de la voz del locutor puede ser frecuente (...) al cantar un gol, es decir, al ejercer el propio sonsonete que caracteriza a cada locutor. Para evitarlo, pues no es una práctica beneficiosa a la larga, debemos dominar nuestra extensión tonal y mantener un buen entrenamiento que evite ese quiebro involuntario de la voz (...).

Forzar la tonalidad de la voz puede resultar interesante para la narración, pero nunca en exceso o sin control". ${ }^{14}$

Volvemos a recalcar aquí la necesidad de la formación vocal y la práctica diaria de la técnica vocal para prevenir disfonías y aprender a utilizar de forma eficaz la voz.

A pesar de estas recomendaciones, no debemos olvidar que el deporte se concibe como un espectáculo, que además vende, y que por ello su narración también debe ser un espectacular. Pero este hecho, no significa que se abuse de malos hábitos, sino que al contrario, para hacer espectacular una narración deportiva, ésta deberá ser narrada dejando de lado las malas prácticas.

Que una narración sea espectacular es correcto, que un programa deportivo quiera ser similar a una retransmisión de un partido, en lo que al tono y a la intensidad se refiere, es totalmente incorrecto.

En lo que respecta a la improvisación, una retransmisión deportiva siempre un acto no planeado, pero ello no quiere decir que se dejen de lado todas las pautas generales de locución, así como tampoco la buena estética de los mensajes. Blanco, J.M. afirma que: "la brillantez y efectividad de su elaboración dependerá de un entrenamiento previo y de una experiencia acumulada" 15 .

No quiero dejar de prestar atención a una reflexión personal que nos nace, no derivada del estudio, sino de la práctica profesional: un buen locutor debe aunar formación académica,

${ }^{13}$ BLANCO,J.M. (2002) Las retransmisiones deportivas: técnicas de narración radiofónica. Comunicación Global, Barcelona. Pág. 89

${ }^{14}$ BLANCH, Margarita; Lázaro, Patricia. “Aula de locución”. Cátedra. Madrid, 2010. Pág. 156.

15 BLANCO, J.M. (2002) Las retransmisiones deportivas: técnicas de narración radiofónica. Comunicación Global, Barcelona. pág. 102. 
vocal y también práctica. Sin repetir y practicar no se consigue ni siquiera acercarse al camino de las buenas formas.

\subsubsection{Entrevista con Emma Rodero Antón ${ }^{16}$}

Durante nuestro estudio hemos tenido la oportunidad de entrevista a la Doctora en Ciencias de la Información por la Universidad Pontificia de Salamanca, Emma Rodero Antón. Algunas de sus obras han sido bibliografía obligada para este estudio.

A continuación expondremos las respuestas más significativas que nos ha dado a las cuestiones realizadas y que toman relación con lo que se viene desarrollando en este apartado del trabajo.

Opinión general sobre las narraciones...

"La narración de un partido de fútbol, bajo mi punto de vista, en la radio se hace muy bien, porque suple a nivel tonal la falta de imagen. Por eso, la mayoría de la gente ve los partidos por televisión pero los escuchas por la radio. Eso es un síntoma de que algo va bien, y eso es importante. Utilizan un tono relativamente agudo para llamar la atención, pero lo más importante a tener en cuenta es saber manejar la voz en función de lo que está pasando en el terreno de juego".

Técnica vocal....

"Hay algunos locutores deportivos que tienen mejor técnica que otros, y eso hace que los que no la poseen se queden sin voz al día siguiente, porque pegan tres chillidos en varios goles y no pueden recuperarse. Para evitar quedarse sin voz durante la narración de un partido debe practicarse la técnica vocal. Hay varios recursos para "gritar", aunque tampoco se trata de gritar, ya que tienes un micrófono delante que amplifica el sonido de tu voz. Puedes utilizar determinadas técnicas para no tener que chillar nunca y que te cause disfonía. Además, pueden utilizar una buena base respiratoria, además de muchas técnicas utilizadas por los actores, para poder gritar sin tener que quedarse sin voz".

Formación vocal...

"El problema es que, como nadie tiene ese tipo de formación y esa educación vocal, al segundo chillido que meten en un partido se quedan sin voz. Hace mucho tiempo los locutores se formaban en técnica vocal. Hay toda una generación que viene de Radio

${ }^{16}$ Dios García, Escarlata (2012, junio) Entrevista con Emma Rodero Antón, Doctora en Ciencias de la Información por la Universidad Pontificia de Salamanca 
Juventud o de una serie de radios existentes en ese momento donde se les daban cursos de locución. Esos locutores estaban más formados de lo que podrían estar ahora, porque en realidad en las facultades de comunicación nos queda mucho camino por avanzar".

La importancia de la locución deportiva...

"En las facultades de comunicación la locución se trabaja muy poco. Yo siempre digo que la locución deportiva, que es una especialización, es esencial para saber manejar bien la voz, porque necesita tal requerimiento vocal que es importantísimo trabajarla. La gente que no se quiera dedicar a los deportes también debería de pasar por hacer una retransmisión deportiva, porque viene muy bien para obtener un juego vocal muy variado".

La unión entre la figura de redactor y locutor...

"Esta unión, que se ha llevado a cabo en los últimos tiempos, sería positiva si se formara la figura del locutor. Hubo un momento en España en el que se separaron las dos figuras, lo que conllevó el "desaparecimiento" del locutor, ya que aunque no ha desaparecido del todo, da la impresión que sí, porque entra a formar parte de la redacción. Ahora existen un montón de periodistas que están muy formados desde el punto de vista del criterio informativo, pero que les falta la parte de la forma. Ahí comienza la lucha, ¿preferimos un locutor de los de antes, una voz que sólo lee? o ¿queremos un escritor que no sepa leer? Lo que queremos ahora son las dos cosas".

¿Cómo presentar un programa deportivo?...

"Al hacer la presentación del programa siempre tienes que hacerlo más animado, en un tono más agudo y más acelerado. Todo ello siempre que se esté introduciendo un programa para hablar de un partido que se está llevando a cabo en ese momento. Si se trata de la programación normal, un programa donde se van a dar los sonidos más relevantes de esa jornada, un día puedo empezar por arriba y otro por abajo, lo importante es que no sea regular. También esto va a depender del estilo del presentador. Es decir, si el locutor siempre comienza de la misma manera porque es su signo de identificación, entonces es correcto. Pero si no pues cada día puede empezar de forma diferente. Lo importante es tener recursos para empezar de forma diferente".

¿Cómo debe formarse un periodista para ser un buen locutor deportivo?... 
"Puesto que es un deporte de riesgo, teniendo una buena técnica vocal. Esto es fundamental, más tratándose de un ámbito donde es muy probable que posteriormente se tengan problemas con la voz. El periodismo deportivo debería ser una especialidad contemplada como tal y dentro de ella debería trabajarse la locución. La técnica vocal es fundamental, al igual que la expresividad".

\subsubsection{Consejos para cuidar la voz de los profesionales deportivos}

Hemos contactado con una logopeda especializada en el cuidado de la voz, González Hernández, Rocío., que nos ha detallado algunas de las recomendaciones que deberían seguir los locutores y narradores para cuidar ${ }^{17}$ su voz.

Es fundamental para un locutor conocer su instrumento vocal para sacarle el máximo partido y modelar su voz mejorando sus cualidades estéticas. Recomendamos conseguirlo a través de cursos especializados o entrenamiento individualizado. Debería incluir:

- Ideas básicas sobre la producción de la voz.

- El funcionamiento laríngeo.

- La respiración diafragmática. Interiorizarla en lectura y en el habla espontánea, para que la respiración sea insonora y suficiente para toda la frase.

- La importancia de los órganos articulatorios y resonadores.

- Medidas de cuidado de la voz.

- Entrenamiento de las cualidades de la voz: intensidad, tono timbre y duración.

- Ejercicios de calentamiento y entrenamiento vocal.

- Trabajo sobre las consonantes para conseguir una articulación clara.

- Trabajar sobre textos con dificultad articulatoria: trabalenguas, textos con palabras complejas, textos para ampliar la capacidad respiratoria.

- Trabajo sobre el tono vocal ampliando la tesitura y poder alcanzar tonos elevados como los necesarios para cantar un gol.

\footnotetext{
${ }^{17}$ Dios García, Escarlata (2012, septiembre) Entrevista con Rocío González Hernández, logopeda y profesora de Técnica Vocal en el "Centro Mencey" (IPRA). Santa Cruz de Tenerife.
} 


\section{CALENTAMIENTO VOCAL PREVIO A UNA NARRACIÓN}

- Calentamiento vocales con consonantes relajantes como $/ \mathrm{m} / \mathrm{o} / \mathrm{n} /$

- Emitir estas consonantes haciendo una escala de 7 tonos.

- Imitar el sonido de una sirena

- Realizar movimientos de agilidad de lengua y labios $\longrightarrow$ "praxias"

- Calentamiento de la respiración

\subsubsection{La "voz" de los profesionales del periodismo deportivo de los medios de comunicación en Tenerife}

Como hemos visto hasta ahora, un locutor, y en concreto un locutor eportivo, que es el objeto de nuestro estudio, necesita de una buena formación vocal para poder enfrentarse a un micrófono y transmitir su mensaje de forma efectiva.

Para llevar a cabo este estudio, hemos realizado un repaso por las generaciones del periodismo radiofónico deportivo de Tenerife y los locutores nos han explicado que, la formación vocal es primordial para narrar. Esta formación derivará en un buen cuidado de la voz, lo que es imprescindible para desarrollar la actividad radiofónica.

De este breve acercamiento a los comunicadores que han desarrollado su labor en las diferentes radios y medios de comunicación de Tenerife, hemos sacado algunas conclusiones $^{18}$ :

- La vocalización, el tono y el ritmo son puntos muy importantes a la hora de ponerse frente a un micrófono.

- Muchos de los locutores entrevistados reconocen que la mala utilización de la intensidad en la narración puede provocar una distorsión en el mensaje.

- La mayor parte de locutores de radio deportiva en Tenerife consideran imprescindible la formación vocal para locutar, así como prestar un especial interés al cuidado de la voz.

\footnotetext{
${ }^{18}$ Para consultar las entrevistas y las respuestas dadas por los entrevistados se recomienda dirigirse al proyecto del que está sacado este artículo. Consultar en la biblioteca de Ciencias de la Información de la Universidad de La Laguna o a la propia autora.
} 
- Aunque muchos han realizado cursos de locución y técnica vocal, no todos han tenido la oportunidad de formarse y tratar su voz.

- En general, los locutores entrevistados reconocen que no se cuidan tanto la voz como debieran, aunque lo consideran fundamental y optarían por que fuera la tónica habitual.

\subsubsection{Características de un buen narrador deportivo.}

Para comenzar a enumerar cuáles son las características de un buen narrador deportivo, primero debemos saber que es la narración, por qué es tan relevante en el entorno de la comunicación y lo que se conoce como la figura del narrador. Según Cebrián Herreros, citado a su vez por Josep María Blanco, una narración es un reportaje en directo:

"Es un relato sometido a un ritmo y a una presentación de los hechos en orden progresivo, o sea, pasando de unos datos a otros de tal manera que siempre haya una aportación nueva que reclame renovadoramente la atención de los seguidores. Se necesita un conocimiento de los recursos narrativos del medio" ${ }^{\prime 19}$.

Debemos saber qué es un narrador, ya que no siempre la figura del periodista y la del narrador se aúnan. Domingo Álvarez ${ }^{20}$, habla de ello: "Periodistas podemos ser todos, habrá periodistas que hagan una magnífica información política, periodistas que hagan una magnífica transmisión de una sesión parlamentaria, y luego hay narradores".

Según, Blanco, J.M.: "un narrador deportivo es en realidad el creador de un universo, de una historia, de un acontecimiento, de unos hechos no vividos por quienes escucha, pero que desde ese momento formarán parte de su realidad". Es decir, que podemos afirmar que un narrador es el que nos acerca, a través de las ondas radiofónicas, al momento que se está viviendo en un lugar en el que no estamos presentes. Si el oyente no puede estar presente en el lugar donde se disputa el partido, el narrador deportivo se lo cuenta. De ahí su

${ }^{19}$ BLANCO, J.M. "Las retransmisiones deportivas: técnicas de narración radiofónica". (2002) Comunicación Global, Barcelona.

2020 Dios García, Escarlata (2012, agosto), Entrevista con Domingo Álvarez Febles, director de Radio Nacional de España en Canarias y narrador de la selección española de Baloncesto en los Juegos Olímpicos de 2012. Santa Cruz de Tenerife 
importancia, "La figura del narrador viene justificada, ante todo, por la existencia, por la actitud y las necesidades de quien escucha"21

Es vital saber que, con el paso del tiempo, el estilo de las narraciones radiofónicas, también en Tenerife, han ido evolucionando y se han adaptado a los "carruseles" más modernos. Sin embargo, con esta evolución, se ha ido perdiendo calidad en la voz. Domingo Álvarez ${ }^{22}$ nos habla de ejemplos como el narrador tinerfeño, César Fernández Trujillo de Armas, de quien hablaremos más tarde, o Juan Hernández.

"César Fdez. Trujillo era para mí un maestro, un modelo. Juan Hernández era un magnífico narrador también y a mi ese estilo me gustaba. Es un estilo muy descriptivo, un estilo pausado, muy adornado y que te hacía vivir el partido como si realmente lo estuvieras viendo. Estoy seguro que si César viviese o Juan retransmitiese ahora un partido tendrían su mercado. Aquélla fórmula es válida para hoy. Pero ocurre que el $80 \%$ del mercado lo que quiere es la emoción el animador. Eso es lo que quiere la gente, al menos eso es lo que demuestra el EGM"23.

En la actualidad, en muchas ocasiones, las retransmisiones deportivas están integradas, no sólo por el narrador, sino por comentaristas, expertos, etc. En ocasiones, el narrador pierde su rumbo y se transforma en una figura que imparte opinión. En otras, los propios comentaristas se creen periodistas. Por ello, el narrador debe tener muy claro cuál es su papel y cuáles los "deberes" que tiene que realizar.

Para que conozcan cuáles son esas "tareas" y cómo realizarlas, a continuación expondremos algunas pautas que hemos extraído tras las entrevistas.

1. Nacer y formarse.

Según Domingo Álvarez, narrar es un don. "Hay un factor genético incuestionable. Un narrador nace y luego se hace, se forma. Periodistas podemos ser todos, habrá periodistas

${ }^{21}$ BLANCO, J.M. "Las retransmisiones deportivas: técnicas de narración radiofónica". (2002) Comunicación Global, Barcelona. Pág. 44

2220 Dios García, Escarlata (2012, agosto), Entrevista con Domingo Álvarez Febles, director de Radio Nacional de España en Canarias y narrador de la selección española de Baloncesto en los Juegos Olímpicos de 2012. Santa Cruz de Tenerife

${ }^{23}$ Dios García, Escarlata (2012, agosto) Entrevista con Domingo Álvarez Febles, director de Radio Nacional de España en Canarias y narrador de la selección española de Baloncesto en los Juegos Olímpicos de 2012. Santa Cruz de Tenerife 
que hagan una magnífica información política, periodistas que hagan una excelente transmisión de una sesión parlamentaria, y luego hay narradores. Ser narrador es algo que se puede ir aprendiendo, formando, pero la narración es un don. Si no lo llevas en los genes es complicado llegar a ser un gran narrador. Narrar un partido, no te diría que lo narra cualquiera, lo puedes narrar mejor o peor, pero para ser un gran narrador creo que hay un factor genético muy importante"24.

2. Además, de formarse, cuidar la voz ${ }^{25}$

"Lo primero que tiene que hacer un narrador es cuidarse, porque incluso los que tenemos la suerte de que nos afecte menos el tiempo, las temperaturas, salir por la noche, tenemos que cuidar un poco nuestra voz"26.

3. Dar la intensidad ${ }^{27}$ y el tono ${ }^{28}$ adecuado a cada momento.

La narración no debe ser ni absolutamente plana, ya que puede causar aburrimiento, ni tampoco ser "un exaltado y estar gritando todo el tiempo. No es lo mismo si la pelota está en el centro del campo que si está a punto de entrar en la portería. Hay que darle la importancia que tiene cada cosa. No tiene el mismo valor, una falta que un gol, un saque de centro que una tarjeta amarilla, o un momento de partido en el que no está pasando nada, que otro en el que están pasando un montón de cosas"29.

${ }^{24}$ EGM: Estudio General de Medios.

${ }^{25}$ A este hecho ya le hemos prestado atención durante la primera parte, pero volvemos a recalcarlo, con el fin de que se tenga en cuenta.

${ }^{26}$ Dios García, Escarlata (2012, agosto) Entrevista a Juan José Ramos González, redactor del periódico "El Día" y locutor de "ABC PUNTO RADIO". Santa Cruz de Tenerife.

${ }^{27} 27$ Intensidad: Según Emma Rodero Antón, "la intensidad de la voz es la cualidad de la voz que se define por la fuerza o potencia de emisión de la voz, dependiente de la presión que el aire ejerce sobre las cuerdas vocales. Esta presión provoca que los pliegues vocales describan unas vibraciones con mayor o menor amplitud. Si la amplitud de la vibración resulta muy escasa, no se produce sensación auditiva puesto que la intensidad sería leve. Por el contrario, si la amplitud es demasiado grande, puede producir dolor, o incluso llegar a dañar el oído, ya que resulta un sonido de enorme intensidad" (RODERO ANTÓN, EMMA) (2003): 408

${ }^{28}$ Tono: el tono de la voz es aquella cualidad "determinada por la altura o elevación de la voz que resulta del número de veces por segundo, aumenta su tensión, la voz se eleva y, en definitiva, se escucha más aguda. En cambio, menos vibraciones por segundo provocan una menor tensión de las cuerdas vocales, entonces la voz desciende y, por tanto, se percibe más grave". (RODERO ANTÓN, EMMA) (2003): 408

${ }^{29} 29$ Dios García, Escarlata (2012, agosto) Entrevista a Juan José Ramos González, redactor del periódico "El Día" y locutor de "ABC PUNTO RADIO". Santa Cruz de Tenerife.

Facultad de Ciencias de la Información - Universidad de La Laguna

Avenida César Manrique, s/n; Campus de Guajara

38071 La Laguna, Tenerife (Islas Canarias - España) 
Domingo Álvarez afirma que una buena narración será aquella donde el tono no sea: "ni muy aburrido ni un tono fuera de lugar. Yo soy de los que cree en las transmisiones con ciertas dosis de alegría, porque si no te aburre, sobre todo si el partido no acompaña. No puedes transmitir un partido de fútbol intentando imprimir emoción desde que el portero le da la pelota al recogepelotas. Cuando se narra un partido se trata de llevarlo como si tuvieras un coche de cinco o seis velocidades. La velocidad va en función de donde esté el balón en cada momento y de cuál sea el resultado. Vamos yo creo en una transmisión así, una transmisión súper animada. Un partido tedioso es un sufrimiento".

4. Fluidez mental y verbal.

"Hay que tener una gran fluidez mental y verbal. Para transmitir, insisto, al nivel de los grandes narradores de este país. Con ello logras, transmitir fielmente lo que estás viendo, con el mayor lujo de detalles, así como con la mayor agilidad posible, talento, frescura e imaginación. Una transmisión fiel al cien por cien de lo que estás viendo, con máxima agilidad y con gran talento" ${ }^{30}$.

5. Introducir contenido que tenga vinculación con la cultura o el patrimonio del lugar donde se está llevando a cabo la narración.

Según José Antonio Pardellas Casas se deben "introducir temas o materias, si no al margen de deporte, que también tengan vinculación con el lugar desde el que se transmite. Si por ejemplo estás narrando desde Toledo, conocer su cultura y su patrimonio e insertar datos sobre este en la narración. Yo recuerdo a un veterano Matías Prats 'padre' que en un momento en el que estaba parado el juego, vio pasar un avión y para rellenar los tiempos huecos dijo-y comienza a simular la narración parecida a lo que pudo ser como ejemplo-" y ahora está pasando sobre el cielo de Madrid, justo a la altura del campo del Real Madrid, un avión de las fuerzas armadas, que posiblemente se dirija a nuestras posesiones, (en aquél momento) del África Occidental española, porque hay un pequeño conflicto (...)perdonen ustedes que dificulte un poco la narración deportiva (...). Con ello, rompía un poco si no la monotonía, (...) y aportaba un dato nuevo que distraía al oyente" ${ }^{31}$.

\footnotetext{
${ }^{30}$ Dios García, Escarlata (2012, agosto) Entrevista con Domingo Álvarez Febles, director de Radio Nacional de España en Canarias y narrador de la selección española de Baloncesto en los Juegos Olímpicos de 2012. Santa Cruz de Tenerife

${ }^{31}$ Dios García, Escarlata (2012, marzo) Entrevista con José Antonio Pardellas Casas, en ese momento era Director de Radio Isla, ya desaparecida. Santa Cruz de Tenerife.
} 
6. Buena interpretación de lo que está sucediendo en el terreno de juego.

No hace falta ser un experto en fútbol, aunque sí dominar la materia de la que se va a hablar para poder interpretar lo que ocurre en el terreno de juego. Debemos explicar bien lo que sucede, y nunca obviar, o por el contrario, inventar, alguna situación.

"Nosotros muchas veces cometemos el error de interpretar mal lo que estamos viendo, de exagerar en algunos momentos o de quedarnos cortos en otros. Hay que interpretar bien el juego. Esto no quiere decir saber de fútbol, esta no es nuestra función. Lo que el narrador esté contando, lo que esté describiendo, que lo describa bien".

Es importante también el estado de ánimo, la concentración, las condiciones de trabajo, etc. Hay veces que te encuentras dificultades en los terrenos de juego: la cercanía del aficionado, problemas con tu línea RDSI, con tu equipo técnico, etc. Existe un montón de cosas que te pueden descentrar un poco"32.

\section{Seguridad en la narración}

Para esto es importante cumplir todos los requisitos mencionados anteriormente. Si el narrador tiene seguridad en la narración, el oyente captará esa seguridad y viceversa. Por ello, cuando el narrador se pone ante un micrófono en cualquier terreno de juego, debe cuidar su voz, saber utilizarla con el tono y la intensidad adecuados, tener fluidez mental y verbal e interpretar bien lo que está sucediendo. Y por todo esto, es necesaria una formación previa, tanto cultural como vocal. Todo ello transmitirá seguridad al oyente, que prestará atención y será testigo de lo que está ocurriendo.

Recordemos que la radio es el vehículo de transmisión de la información que con más facilidad llega a la masa social. Ni siquiera las redes sociales son capaces de ello, puesto que se necesita cierto nivel de aprendizaje tecnológico para poder usarlas. Por esto es importante, saber utilizar bien las herramientas fundamentales con la que procedemos a contar lo que está sucediendo en un determinado lugar.

Estas son sólo algunas de las pautas que debería seguir el narrador deportivo con el objeto de realizar de la mejor forma posible su transmisión.

32 Dios García, Escarlata (2012, agosto) Entrevista a Juan José Ramos González, redactor del periódico "El Día" y locutor de "ABC PUNTO RADIO". Santa Cruz de Tenerife. 


\section{Resultados}

\subsection{Estudio sobre la locución en Tenerife}

Con este estudio hemos intentado dar una demostración empírica de lo que hemos venido desarrollando durante los apartados anteriores de este artículo, sobre las normas y reglas generales de la técnica vocal, la importancia del cuidado de la voz, así como la de la formación vocal para llegar de forma más eficaz a los oyentes que escuchan radio deportiva.

No vamos a explicar el estudio en su conjunto $^{33}$, lo que si vamos es a exponer las conclusiones y los datos más relevantes del análisis realizado.

En primer lugar, debemos señalar que para llevar a cabo el estudio, los encuestados escucharon tres muestras de tres locutores de diferentes generaciones y con distintos modos de locutar. Entre las preguntas sobre los audios se cuestionaba por la locución que más agradaba y por cuál captaba más la atención del público. La muestra más escogida como la locución que más agradaba, por un $69 \%$ de los encuestados, fue la correspondiente a la $A$.

Se trataba de un audio donde se podía escuchar una voz que narraba un partido dinámico, de forma atrayente, con un ritmo ajustado en todo momento a la sucesión de los hechos y que contaba con un tono y una intensidad adecuados fielmente lo que sucedía sobre la cancha. Muchos de los encuestados, así la han descrito. La muestra "B" obtuvo el 25 \% y la "C"34 el 6\% restante.

Contradictoriamente, fue la muestra "B", la elegida como la que más captaba la atención de los oyentes, con un $63 \%$ frente al $38 \%$ que representa a la "A". Según los encuestados, este audio atrae porque la manera de locutar imprime sentimiento y emoción al partido.

Es destacable señalar que todos los encuestados estiman necesaria la formación vocal para los locutores deportivos.

Por los resultados extraídos, podemos afirmar que una buena dicción, una narración dinámica y que cuente fielmente lo que esté ocurriendo, así como una locución con un tono y

\footnotetext{
${ }^{33}$ Para ver el estudio completo volvemos a remitir a los lectores del artículo al proyecto del que parte este artículo.

${ }^{34}$ Debemos señalar que la muestra "C" corresponde a una narración de los años 60 , de un locutor de la que denominaremos como primera generación del periodismo radiofónico deportivo en Tenerife y los cambios y la evolución en la locución pudieron influir a la hora de la elección por parte de los encuestados.
} 
una intensidad ajustada al momento del partido, sin gritos y donde la técnica vocal se cuida sería la más conveniente, todo ellos, claro está, unido a la emoción y el sentimiento que debe imprimir el narrador para captar la atención. La mezcla de todas las formas adecuadas de la narración de la muestra "A" y la emotividad de la "B" harían un cóctel que posiblemente pueda provocar que el oyente se sienta cómodo y elija nuestra cadena, lo que se traduciría en beneficios económicos, necesarios en la época que corre.

\subsection{La evolución de la locución deportiva en Tenerife a través de tres generaciones de locutores}

Tras la realización las entrevistas y la redacción de los tres apartados anteriores hemos realizado un pequeño resumen ${ }^{35}$ para este artículo, con el fin de explicar cuáles han sido las líneas generales de evolución de la locución deportiva en Tenerife desde los años 60 del siglo XX hasta la actualidad.

La primera generación de periodistas y locutores deportivos en Tenerife no contaban con una enseñanza universitaria en periodismo, pero sí con una formación especializada en locución y técnica vocal que se llevaba a cabo dentro de las propias emisoras. Es el caso de César Fernández -Trujillo de Armas, quien se formó en la Estación Escuela de "Radio Juventud de Canarias", aunque ya había adquirido algunas pautas generales de dicción durante su estancia en el Seminario ${ }^{36}$. Locutores como José Ramos, Avelino Montesinos, Juan Hernández, Arturo Rodríguez o Carlos Argüelles, entre otros pertenecen a esta "primera generación".

La formación vocal derivaba en unas voces exquisitas y que con el paso del tiempo, aún siguen estando presentes en la memoria de muchos de los profesionales de los medios de comunicación y oyentes que las han escuchado.

Sin embargo, esta época no se caracterizaba por las tecnologías, que aún se encontraban "entre pañales". En muchos casos, los locutores se las veían para poder realizar con cierta calidad una retransmisión deportiva, y es que, las líneas microfónicas no siempre

\footnotetext{
${ }^{35}$ El estudio de casos de las diferentes generaciones se puede consultar en el proyecto del que parte este artículo. Para consultar más información acerca de las cuestiones con esta parte del documento, volvemos a remitir a la autora del mismo.

${ }^{36}$ Se puede leer más sobre César Fernández-Trujillo de Armas en el libro escrito por el periodista César Fernández-Trujillo Castro, "Amigos Oyentes". Esta obra, junto a una entrevista realizada al propio escritor y periodista, ha sido bibliografía básica para el proyecto de investigación del que parte este artículo.
} 
funcionaban correctamente. En más de una ocasión los comunicadores no sabían si se les estaba escuchando o no, pero a pesar de ello, desempeñaban una labor encomiable durante, por ejemplo, los 90 minutos de un encuentro de fútbol.

La segunda generación se caracteriza por voces como la de Salvador García Llanos o Domingo Álvarez, que a pesar de pasar 10 años entre el comienzo de la andadura profesional entre uno y otro, han compartido y comparten muchas características que, sin duda, representan a esta segunda generación.

Los recursos económicos seguían siendo escasos por 1970, así como las tecnologías, que habían avanzado pero no son comparables con las que disponen los narradores en la actualidad. Las conexiones se hacían a través de la Compañía Telefónica Nacional de España, y en muchas ocasiones el turno de guardia que hacía las conexiones mediante la llamada "Mesa de Pruebas" se retrasaba o no estaba, lo que provocaba que los locutores entraran en directo sin saber si desde el estudio se le escuchaba o no.

Esta segunda generación aún pudo formarse en cursos especializados dentro de las propias emisoras. "Radio Juventud de Canarias" seguía impartiendo cursos a los que pudo asistir de forma gratuita, por ejemplo, Domingo Álvarez. El curso del que era profesor Juan Hernández, le abrió la puerta al, hasta hace poco Director de Radio Nacional de España, para comenzar su carrera profesional en la narración deportiva.

No podemos olvidar destacar entre esta segunda ola de profesionales de la radio deportiva a Juan Carlos Hernández, Xuancar, María Luisa Arozarena o José Manuel Pitti, entre otros.

La que en este artículo denominamos tercera generación aúna a muchos profesionales y muchas voces que, todavía hoy, siguen formando parte del elenco de profesionales de los medios de comunicación. Ya en esta tercera generación, no se le presta tanta importancia a la figura del locutor, y locución y redacción se unen en las emisoras. La formación dentro de las propias emisoras continúa existiendo, pero no es la tónica habitual. Mayte Castro, por ejemplo, recuerda como en "Radio Club Tenerife" se impartían cursos de locución. Asunción Hernández nos comentaba en la entrevista que le realizábamos, para el proyecto de investigación, que en la ya desaparecida "Antena 3 Radio" le enseñaban a locutar, redactar, producir un programa, etc.

En esta época las tecnologías comienzan a desarrollarse de forma importante, muchas veces se hacían inalámbricos con móvil, pero aún se siguen utilizando las líneas microfónicas para las retransmisiones o papeles en blanco desde las cabinas para dar paso, según nos cuenta de forma anecdótica la propia Asunción Hernández. 
La última etapa hasta la actualidad se caracteriza por un gran avance en tecnología, la línea RDSI, que permite unas conexiones más nítidas. En los últimos años, Internet, la línea ADSL, o los móviles de última generación han favorecido la calidad de la radio en general. Conexiones por ADSL vía IP y el manejo de las redes sociales han otorgado calidad en el sonido e instantaneidad en los mensajes.

La voz ha quedado en un segundo plano. Lo que se necesita es un redactor "todoterreno" que domine las nuevas tecnologías. La formación vocal es casi inexistente en los redactores y locutores deportivos, así como en otras áreas en general, en Tenerife.

La calidad de las voces, por tanto, ha sufrido un retroceso, pese a que han aumentado los recursos económicos y en Tenerife se dispone de una Facultad de Ciencias de la Información.

\section{Conclusiones}

Ha quedado demostrado como la formación vocal es imprescindible y determinante para un periodista deportivo. Tanto los diferentes periodistas y locutores de los medios, así como los profesionales de la voz han argumentado una a una las razones del deber que tienen los comunicadores de formar su voz. Además, en el posterior estudio realizado hemos visto como la audiencia también pide comunicadores con voces formadas. Una buena voz no basta para la radio. Debe haber voces formadas y cuidadas. Esto cobra especial relevancia en el ámbito de la radio deportiva, pues los narradores, antes más, ahora ya menos, suelen verse expuestos a innumerables circunstancias que pueden provocar la distorsión del mensaje. No es conveniente hacer de la voz una más.

En lo que respecta al cuidado que le dan los profesionales del medio radiofónico deportivo en Tenerife a la voz, podemos decir que es escaso. Existe pues, una carencia de las bases que debería seguir el locutor deportivo, bien por propio desinterés, o por falta de cuidado por parte de las emisoras a la hora de formar a sus locutores en la práctica. Hemos comprobado como todos admiten la importancia de las buenas prácticas y el desarrollo de una buena técnica vocal, pero hemos podido comprobar que la inmensa mayoría no suele acudir a revisarse su propia herramienta de trabajo, y sólo lo hace en casos extremos.

La ciudadanía, es decir, los oyentes tanto habituales a escuchar radio deportiva como los que no lo hacen prefieren, en su mayoría, voces cuidadas, que impartan profesionalidad, seguridad, narren con veracidad, rigor y que lo hagan con un tono y una intensidad apropiadas. Asimismo, los oyentes no rechazan la emotividad que surge de forma 
espontánea en las narraciones deportivas, sobre todo si se trata de narrar "el equipo de tu tierra".

Por último, no podemos dejar de comentar la evolución que ha experimentado la radio deportiva desde los años 60 hasta la década del 2000.

Cuando locutores como los mencionados César Fernández-Trujillo, Carlos Argüelles, José Ramos, Juan Hernández, Paco Álvarez o muchos otros comienzan en la radio deportiva, los medios económicos para formarse no son muy abundantes. Tampoco existen estudios universitarios en periodismo en Tenerife, ni un lugar donde dedicarse exclusivamente a la formación de la profesión periodística. Sin embargo, observamos unas voces, no sólo espléndidas, que narran con fiel detalle lo que sucede, sino también cuidadas y formadas. Esta formación se recibe en la mayoría de las ocasiones en las propias emisoras, que ven como "hacer crecer" a sus trabajadores también les beneficia.

Con el paso del tiempo, tampoco mejora la situación económica y los periodistas y comunicadores continúan sin recibir una formación adecuada. Sin embargo, siguen surgiendo grandes profesionales y grandes relatores que cada fin de semana mantienen "pegados al transistor" a cientos de oyentes.

En la actualidad, existe Facultad de Ciencias de la Información, e incluso muchos locutores y periodistas salen a estudiar fuera como Beatriz Palmero o Manoj Daswani, pero todos reconocen la existencia de una falta de formación vocal.

La radio deportiva ha sabido sostenerse y crecer a pesar de las continuas dificultades en las que se ha visto inmersa. Los locutores han realizado una labor y un esfuerzo impagable para mantener el respeto que merecen los oyentes. Que las nuevas generaciones, así como los redactores que actualmente se encuentran en las diferentes emisoras de Canarias y España, y sobre todo, en la radio deportiva, que es lo que nos ocupa en este trabajo, tomen conciencia de ello y contribuyan siempre a mejorar el medio radiofónico de forma general y en el ámbito deportivo de forma específica, ya que quienes han escrito la historia de la radio deportiva con su quehacer diario merece ser respetado.

\section{Bibliografía}

ALCOBA LÓPEZ, ANTONIO. "Como hacer periodismo deportivo". Editorial Paraninfo. Madrid, 1993.

ALCOBA LÓPEZ, ANTONIO. "Periodismo deportivo". Editorial Síntesis. Madrid, 2005. 
ALCOBA LÓPEZ, ANTONIO. "La Prensa deportiva". Servicio de Publicaciones de la Universidad Complutense de Madrid. Madrid, 1999.

ÁVILA, ALEJANDRO. "Manual práctico para iniciarse como locutor de radio". Editorial CIMS. Barcelona, 2000.

BLANCO JOSEP $\mathrm{M}^{\circ}$. "Las retransmisiones deportivas. Técnicas de narración radiofónica". Barcelona Digital S.L, 2002.

BIRZ, ANTONIO; ALBELDA, MARTA, FERNÁNDEZ, MARIA JOSÉ."Saber hablar". Santillana Ediciones Generales S.L. Madrid, 2008.

BLACH, MARGARITA; LÁZARO, PATRICIA. "Aula de locución". Ediciones Cátedra, Madrid, 2010

FERNÁNDEZ-TRUJILLO CASTRO, CÉSAR."Amigos oyentes". Ediciones Idea, Santa Cruz de Tenerife, 2012.

GALÁN GAMERO, JAVIER. "Historia del Periodismo Tinerfeño (1900-1931)". Producciones Gráficas, S.L. Santa Cruz de Tenerife, 1997

GALÁN GAMERO, JAVIER. "Historia rápida de la Prensa en Santa Cruz de Tenerife". Tauro Producciones. Santa Cruz de Tenerife, 1995.

GALARZA JUAN; PADILLA LUIS. "EI CD Tenerife en 366 historias. Relatos de un siglo". AyB Editorial, Santa Cruz de Tenerife, 2010.

GALARZA, JUAN; PADILLA, LUIS; ROJAS, JOSÉ; y TRUJILLO, SANTIAGO. "Los Ascenso del CD Tenerife". AyB Editorial, Santa cruz de Tenerife, 2011.

HERNÁNDEZ ALONSO, NÉSTOR. "El lenguaje de las crónicas deportivas". Ediciones Cátedra, Madrid, 2003.

MATEU BARROSO, JUAN CARLOS. "Luces y ondas". AyB Editorial, Santa Cruz de Tenerife, 2010.

MALVAR, LUIS. "La Radio deportiva en España. 1927 -2004". Pearson educación S.A, Madrid, 2005.

MARTÍN, CARLES. "Periodismo Audiovisual. Información, entretenimiento y tecnología multimedia". Gedisa Editorial, Barcelona, 2006

PARDELLAS CASAS, JOSÉ ANTONIO. “¡Oh, la radio!”. Ediciones idea, Santa cruz de Tenerife, 2008. 
RODERO ANTÓN, EMMA. "Locución radiofónica". Servicio de Publicaciones Universidad Pontificia de Salamanca, Madrid, 2003.

RODRÍGUEZ BORGES, RODRIGO FIDEL. "Radio e información. Elemento para el análisis de los mensajes radiofónicos". Servicio de publicaciones Universidad de La Laguna, Santa Cruz de Tenerife, 2006.

YANES, JULIO. "Las ondas juveniles del franquismo". Ediciones baile del sol, Santa Cruz de Tenerife, 2006

YANES MESA, JUAN ANTONIO; RODRÍGUEZ BORGES, RODRIGO FIDEL. "La radiodifusión sindical del franquismo. La voz del valle en las islas Canarias, 1960-1965". Gobierno de Canarias, Cabildo Insular de Tenerife y Ayuntamiento de la Villa de La Orotava. Santa Cruz de Tenerife, 2007.

YANES, JULIO. "Los Orígenes de la radiodifusión en Canarias. Radio Club Tenerife, 19341939". Ediciones Baile del sol, Santa Cruz de Tenerife, 2006.

YANES, JULIO."Los orígenes de la cope en canarias. Radio popular de Güimar". Ediciones baile del sol, Santa cruz de Tenerife, 2006.

YANES, JULIO; HERNÁNDEZ, EDMUNDO." La voz de la isla de la Palma, 1960-1978.La Radiodifusión del subsistema comunicativo más singular de las islas canarias en el franquismo". Ediciones Alternativas, 2011.

YANES, JULIO."Historia del periodismo Tinerfeño 1758-1936. Una visión periférica de la Historia del periodismo español.". Fareso.S.A, Madrid, 2003

\section{- Recursos en línea:}

ÁLVAREZ ABREU, BRUNO JUAN. Blog: "Efemérides"

\section{- Tesis Doctorales:}

GONZÁLEZ ÁVILA, CARLOS. 2010. "Estética de los mensajes audiovisuales: el cine como soporte didáctico", Universidad de La Laguna.

\section{- FUENTES ORALES:}

-Alejandro Arbelo

-Álvaro Castañeda 
-Bruno Juan Abreu Álvarez

-Carmen Beatriz Palmero

-César Fernández-Trujillo Castro

-Clemente Mesa Curbelo

-Domingo Álvarez

-Emma Rodero Antón

-Guillermo García Saavedra

-Ismael Reyes

-Iván Bonales Ferrera

-Javier Fernández Trujillo

-José Antonio Felipe Martín

-José Antonio Pardellas

-Juan José Ramos

-José Manuel Pitti

-Juan Ramón Daswani Padrón

-José Ramos González

-Juan Carlos Castañeda Baute

-Juan Sánchez Quintana (Juan Antonio Sánchez Enrique)

-Lucía Pacheco López

-Luis López González

-María Asunción Hernández

-María Luisa Arozarena

-Mayte Castro

-Manoj Daswani

-Óscar Herrera Angulo

-Ramón Hernández Vera

-Salvador García Llanos 
-Rocío González

\section{Forma de citar este artículo en bibliografías}

DIOS GARCÍA, E. (2012): "La locución deportiva en Tenerife: Evolución y características, Tres generaciones del periodismo radiofónico deportivo", en Revista PANGEA, 3, páginas 133 a 159. Red Académica Iberoamericana de Comunicación. Recuperado el _ de de 2 de: http://www.revistapangea.org 